(C2020. This manuscript version is made available under the CC-BY-NC-ND 4.0 license http://creativecommons.org/licenses/by-nc-nd/4.0/

\title{
A fluorescent probe based on cucurbit[7]uril for the selective recognition of
}

\section{phenylalanine}

Pei-Hui Shan, ${ }^{a}$ Jing-Lan Kan, ${ }^{\mathrm{b}}$ Xin-Yu Deng, ${ }^{\text {a }}$ Carl Redshaw, ${ }^{\mathrm{c}}$ Bing Bian, ${ }^{\mathrm{d}}$ Ying Fan, ${ }^{\mathrm{a}}$ Zhu Tao, ${ }^{\mathrm{a}}$ Xin $\mathrm{Xiao}^{\mathrm{a}^{*}}$

${ }^{a}$ Key Laboratory of Macrocyclic and Supramolecular Chemistry of Guizhou Province, Guizhou University, Guiyang 550025, China

E-mail: gyhxxiaoxin@163.com (X.Xiao)

${ }^{b}$ College of Chemistry, Chemical Engineering and Materials Science, Shandong Normal University, Jinan 250014, China

${ }^{c}$ Department of Chemistry and Biochemistry, University of Hull, Hull HU6 7RX, U.K.

d College of Chemical and Environmental Engineering, Shandong University of Science and Technology, Qingdao 266590, P. R. China.

ABSTRACT: Herein we describe a simple fluorescence quenching method for the selective recognition and determination of the amino acid phenylalanine (Phe). The use of ${ }^{1} \mathrm{H}$ NMR spectroscopy revealed that the alkaloid palmatine (PAL) can encapsulated partially into the cavity of cucurbit[7]uril (Q[7]) in aqueous solution to form a stable 1:1 host-guest inclusion complex. This host-guest complex exhibits fluorescence of moderate intensity. Interestingly, the addition of the Phe results in a dramatic quenching of the fluorescence intensity associated with the inclusion complex. By contrast, the addition of other natural amino acids resulted in no change in the fluorescence. Based on the linear relationship between the fluorescence intensity and the concentration of Phe, the detection of the concentration of Phe in aqueous solution is facile. Thus, a new fluorescence quenching method for the recognition and determination of the Phe has established herein. 
Keywords: Cucurbit[7]uril Supramolecular assembly Selective recognition Fluorescent probe Host-guest chemistry 


\section{Introduction}

Amino acids are one of the most important classes of building blocks for proteins and peptides. ${ }^{1}$ The twenty natural amino acids are widely distributed in food, condiments, pharmaceutical preparations, and even metabolites in the human body.,3 As a consequence, the development of reliable methods for amino acid recognition and determination are of great significance in food testing, nutritional analysis, medical diagnostics, and for numerous other fields..$^{4-9}$ To date, many methods, including high performance liquid chromatography (HPLC), ${ }^{10}$ gas chromatography (GC), ${ }^{11}$ capillary electrophoresis (CE), ${ }^{12}$ and optical techniques, ${ }^{13,14}$ have been employed for the recognition and detection of the twenty natural amino acids. Among the optical techniques, the fluorescence approach is particular attractive given its excellent selectivity, fast response time, low detection limits, and the inexpensive instrumentation required ${ }^{15}$. Nevertheless, it remains a challenge to develop an effective fluorescent probe system for the detection of specific amino acids.

The synthetic macrocyclic receptors, cucurbit $[n]$ urils (abbreviated as $\mathrm{Q}[n] \mathrm{s}$, Figure 1) comprise $n$ glycoluril units bridged by $2 n$ methylene groups, ${ }^{16-21}$ and possess hydrophobic cavities and carbonyl-laced portals. Cucurbit $[n]$ urils have been shown to bind organic guests in aqueous solution with equilibrium association constant $(\mathrm{Ka})$ values over an enormous range of affinities. ${ }^{22-30}$ In recent years, $\mathrm{Q}[n] \mathrm{s}$ and derivatives thereof have been reported to encapsulate a number of specific amino acids, peptides and proteins. ${ }^{31-40}$ It is well recognized that the encapsulation or release of guests by hosts can bring about substantial alteration in the chemical and physical properties of the guests. ${ }^{41-50}$

' For example, Chang and co-workers demonstrated that the fluorescence of palmatine (PAL) in aqueous solution was greatly enhanced when encapsulated by the cavity of Q[7]. ${ }^{51-54}$ The competitive reaction between target drugs and the PAL for the occupancy of Q[7] cavity can result in fluorescence quenching, and this can be utilized for the recognition of the different drugs. The studies of Chang 
prompted us to investigate whether the PAL probe could be encapsulated within the Q[7] cavity to form an inclusion complex, and then whether the Q[7]@PAL could be used to sense the binding of natural amino acids.

In the present work, we have studied the binding properties of Q[7] towards PAL using a number of techniques including ${ }^{1} \mathrm{H}$ NMR spectroscopy, UV-vis and fluorescence spectroscopy, and isothermal titration calorimetry (ITC), and found that a 1:1 host-guest inclusion complex is formed, which displayed fluorescence of moderate intensity. More importantly, when phenylalanine (Phe) was added to the 1:1 host-guest inclusion complex of Q[7]@PAL, the fluorescence intensity of the inclusion complex was dramatically quenched. However, the addition of any other natural amino acids to the same inclusion complex did not lead to any distinct fluorescence changes. These observations indicate that this system can be used for the selective recognition and determination of Phe in aqueous solution.
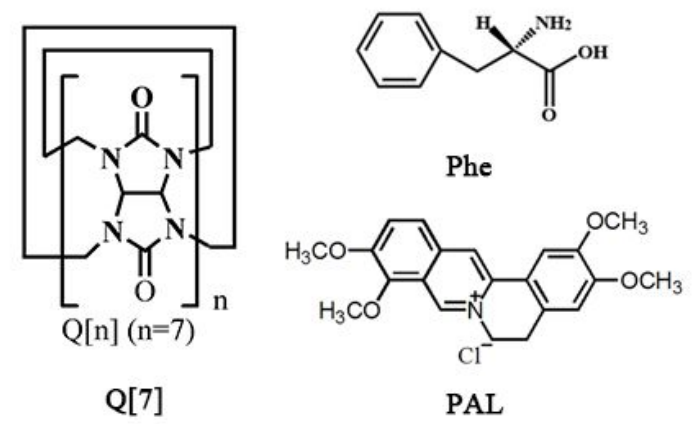

PAL

Figure 1. The molecular structures of Q[7], PAL and the amino acid phenylalanine (Phe).

\section{Results and Discussion}

\section{Formation of 1:1 inclusion complexes in aqueous solution}

The binding properties of Q[7] towards PAL in aqueous solution have been monitored by ${ }^{1} \mathrm{H}$ NMR spectroscopic experiments. Figure 2 shows the ${ }^{1} \mathrm{H}$ NMR spectra of PAL in the absence and in the presence of differing equivalents of $\mathrm{Q}[7]$ in neutral $\mathrm{D}_{2} \mathrm{O}$ solution. Upon the addition of increasing amounts of host Q[7], the $\mathrm{Ha}, \mathrm{Hb} \mathrm{Hc}, \mathrm{Hd}$ and He protons of the PAL were shifted upfield, whilst the Hf, 
$\mathrm{Hi}, \mathrm{Hj}$ protons of the PAL were gradually shifted downfield. This behavior can be rationalized by the inclusion of the methoxy-isoquinoline motif inside the cavity of the host, with the substituted benzene ring remaining outside.

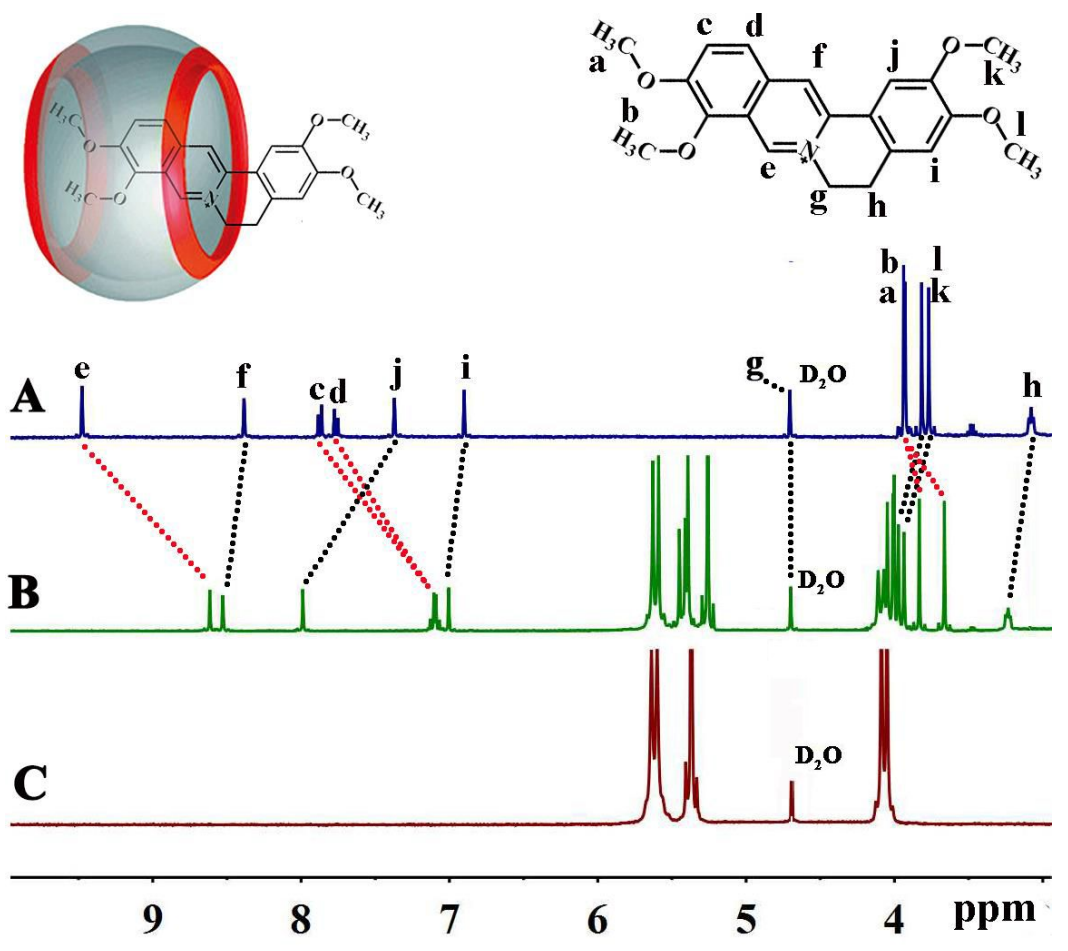

Figure 2. ${ }^{1} \mathrm{H}$ NMR spectra of PAL $(2.0 \mathrm{mmol} / \mathrm{L})$ in the absence $(\mathrm{A})$ and in the presence of 1.02 equivalents of Q[7] (B) and neat Q[7] (C) in $\mathrm{D}_{2} \mathrm{O}$ at $20{ }^{\circ} \mathrm{C}$.

\section{UV-vis and fluorescence spectroscopy}

The binding properties of Q[7] to PAL in aqueous solution was further investigated by UV-vis (Figure 3) and fluorescence (Figure 5) spectroscopic titration experiments. As can be seen in Figure 3, PAL exhibits characteristic absorption peaks at 225, 274, and $343 \mathrm{~nm}$. On gradually adding Q[7], the absorption peak of PAL was red shifted to $279 \mathrm{~nm}$. At the same time, the absorbance intensity of PAL was greatly decreased, indicating the high binding affinity of Q[7] towards PAL. According to the mol ratio method (Figure 3b), the binding interaction of Q[7] with PAL readily fitted a $1: 1$ (host : guest) binding model. A continuous variation Job's plot (Figure 4) further confirmed that the Q[7]/PAL inclusion complex was formed with a 1:1 stoichiometry. 
The fluorescence spectroscopy of PAL also showed a large change upon the addition of Q[7]. It is well known that PAL display no intrinsic fluorescence in aqueous solution, ${ }^{55}$ however, upon the gradual addition of Q[7] the fluorescence intensity of PAL displays a significant enhancement. This observed enhancement is attributed to the formation of a $1: 1$ host-guest inclusion complex in which the Q[7] host provides a hydrophobic microenvironment for the guest ${ }^{56,57}$.
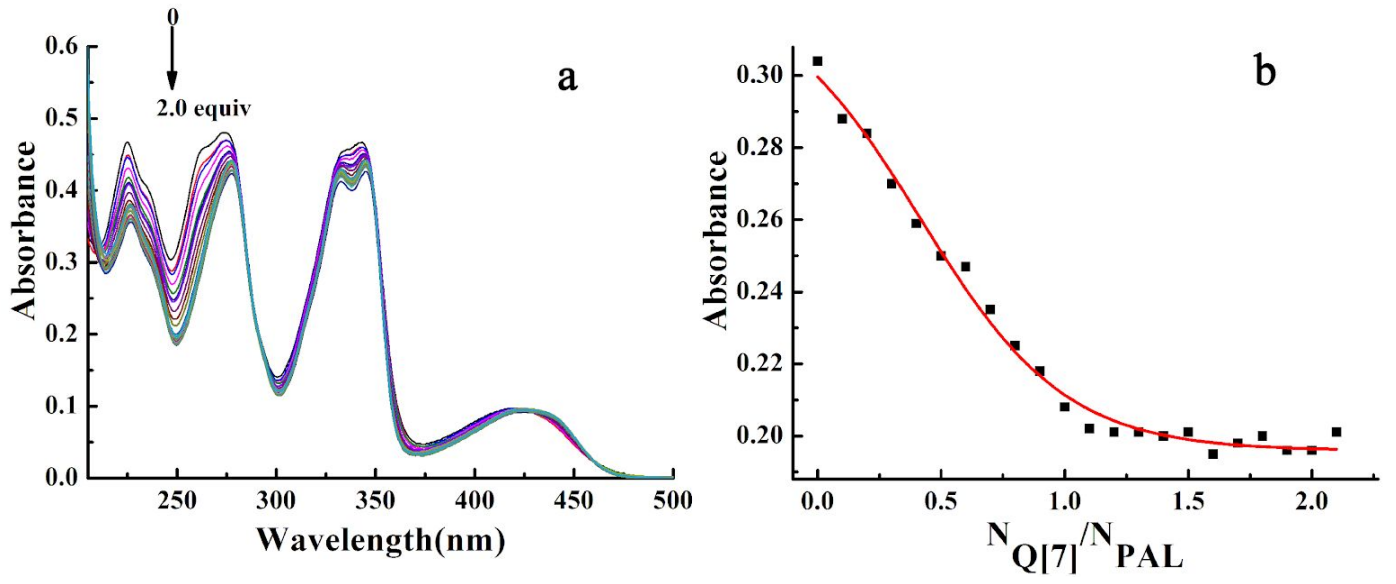

Figure 3. (a) UV-vis titration of PAL $\left(2 \times 10^{-5} \mathrm{~mol} \cdot \mathrm{L}^{-1}\right)$ on increasing concentrations of Q[7] and (b) absorbance (A) vs. the ratio of the number of mol of host and guest $N_{\mathrm{Q}[7]} / N_{\mathrm{PAL}}\left(\lambda_{\max }=247 \mathrm{~nm}\right)$.

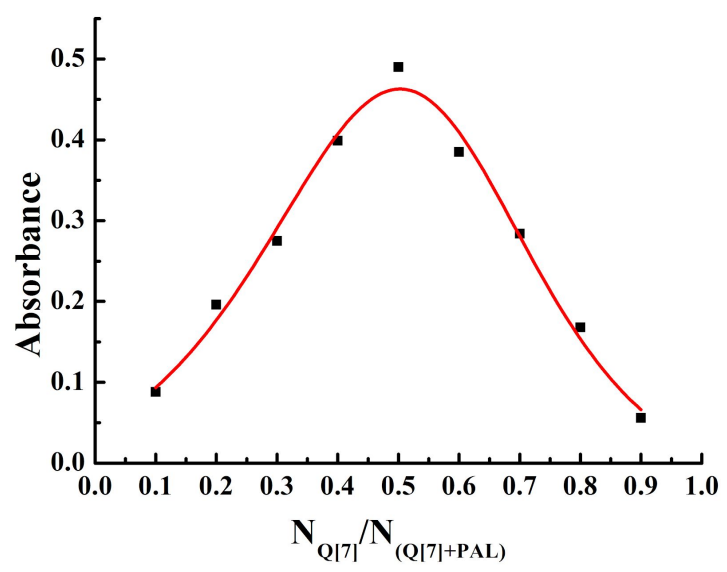

Figure 4. Continuous variation Job's plot for Q[7] and the guest on the basis of UV-vis titration spectra. 

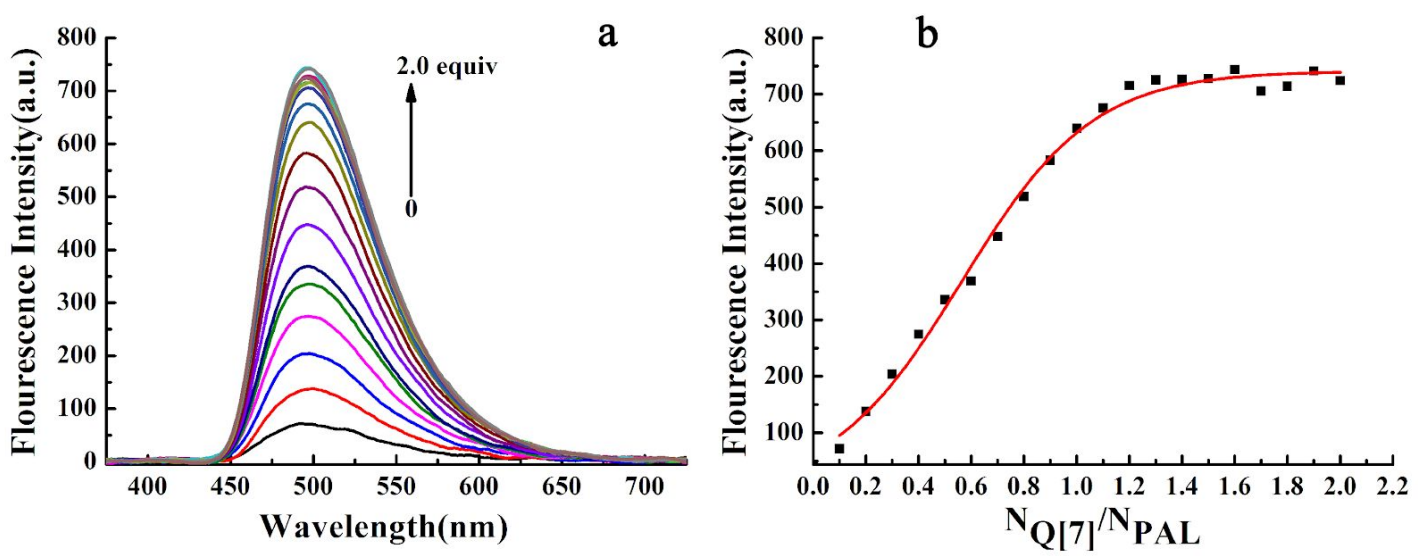

Figure 5. (a) Fluorescence titration of PAL $\left(2 \times 10^{-5} \mathrm{~mol} \cdot \mathrm{L}^{-1}\right)$ on increasing concentrations of $\mathrm{Q}[7]$ and (b) absorbance (A) vs. the ratio of the number of mol of host and guest $N_{\mathrm{Q}[7]} / N_{\mathrm{PAL}}$.

\section{Isothermal titration calorimetry (ITC)}

To further understand the nature of the host-guest complexation of Q[7] with PAL, isothermal titration calorimetry (ITC) experiments (Figure. 6) were carried out. The ITC data revealed that the host-guest complexation is both enthalpically and entropically favorable $\left(\Delta H^{\circ}=-29.14 \mathrm{~kJ} \cdot \mathrm{mol}^{-1}\right.$,

$\left.T \Delta S^{\circ}=5.40 \mathrm{~kJ} \cdot \mathrm{mol}^{-1}, \Delta G^{\circ}=-34.54 \mathrm{~kJ} \cdot \mathrm{mol}^{-1}\right)$. In addition to the ion-dipole interaction between the

positively charged nitrogens on the PAL guest and the oxygen atoms on the portals of the Q[7] host, van der Waals interactions between the surfaces of the PAL guest and the inner wall of the Q[7] host contribute favorable enthalpy toward the host-guest complexation. The removal of the water molecules from the Q[7] cavity and portals, and from the solvated shell of the PAL is likely responsible for this favorable entropic gain. According to the van't Hoff equation $\left(\ln K=-\Delta H^{\circ} / R T+\Delta S^{\circ} / R\right)$ and the enthalpic and entropic values, a large binding constant $(1.12 \pm 0.2) \times 10^{5}$ for Q[7] with PAL is obtained. 


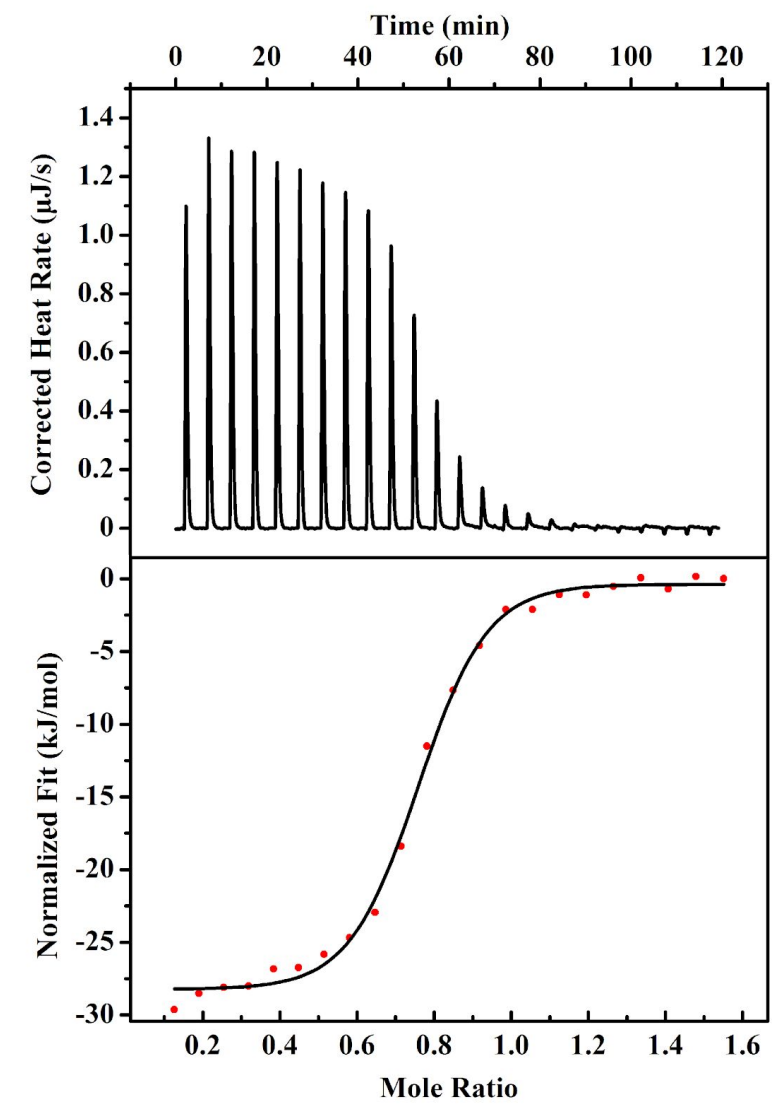

Figure 6. ITC profile of host Q[7] with guest PAL at 298.15 K.

\section{Fluorescence quenching of Q[7]/PAL by Phe}

As mentioned above, PAL does not display native fluorescence in aqueous solution. Whereas when PAL was encapsulated into the Q[7] cavity, the resulting inclusion complex emits fluorescence of moderate intensity. To ascertain whether this inclusion complex PAL@Q[7] can be used to recognize natural amino acids, we carried out a series of fluorescence measurements. Interestingly, when Phe $\left(1 \times 10^{-4} \mathrm{~mol} \cdot \mathrm{L}^{-1}\right)$ was added to the $1: 1$ inclusion complex of Q[7] $\left(2 \times 10^{-5} \mathrm{~mol} \cdot \mathrm{L}^{-1}\right)$ with PAL $\left(2 \times 10^{-5}\right.$ $\left.\mathrm{mol} \cdot \mathrm{L}^{-1}\right)$, the fluorescence characteristic of the inclusion complex PAL@Q[7] showed dramatic changes, and fluorescence quenching was observed. However, the addition of any of the other 19 natural amino acids $\left(1 \times 10^{-4} \mathrm{~mol} \cdot \mathrm{L}^{-1}\right)$ failed to afford any distinct changes in the fluorescence(Figure 7$)$. These observations suggest that the inclusion complex PAL@Q[7] can be used for the selective recognition of the Phe in aqueous solution. 


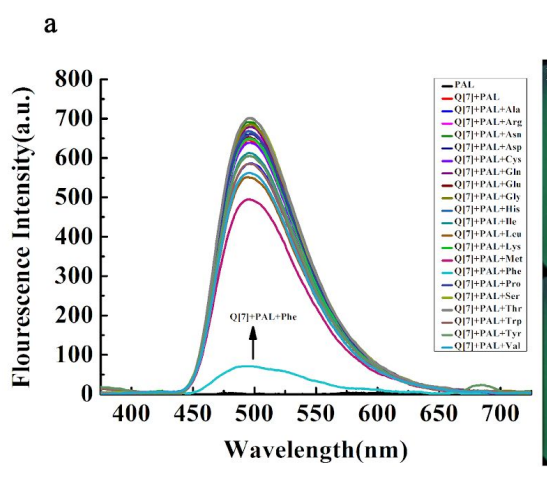

b

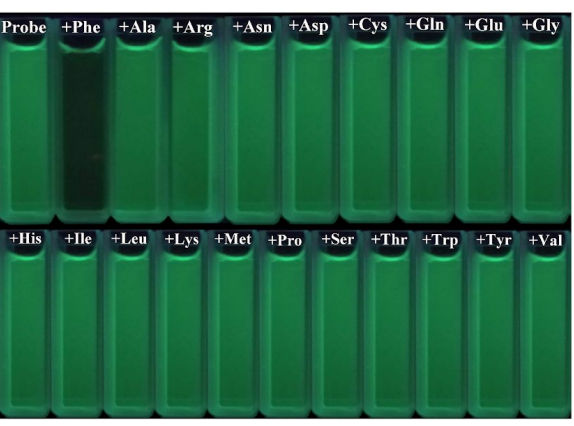

Figure 7. (a) The fluorescence spectra of Q[7]/PAL with different amino acids in aqueous solution with $\lambda_{e x}=343 \mathrm{~nm}$. (b) The photographs of different L-amino acids was added in Q[7]/PAL under exposure to UV light $(365 \mathrm{~nm})$.

\section{Effect of Phe concentration on the fluorescence intensity of the Q[7]/PAL complex}

The effect of varying the Phe concentration on the fluorescence intensity of the Q[7]/PAL complex was also investigated. The concentrations of Phe were varied from 0 to $10 \times 10^{-5} \mathrm{~mol} \cdot \mathrm{L}^{-1}$, and the fluorescence intensity of the Q[7]/PAL complex was found to gradually increase as the Phe concentration increased (Figure 8). It is worth mentioning that the fluorescence intensity (F) exhibited a near linear relationship with the Phe concentration over a certain range of concentrations (from 0 to $\left.2.0 \times 10^{-5} \mathrm{~mol} \cdot \mathrm{L}^{-1}\right)$. The linear range was $0-2 \times 10^{-5} \mathrm{~mol} \cdot \mathrm{L}^{-1}$. and the linear regression equations were $\mathrm{F}=$ 12.4091C+86.6569 (C denotes the concentration $\left(\mathrm{mol} \cdot \mathrm{L}^{-1}\right)$ of Phe) with correlation coefficients of 0.9908, which indicated near linearity.
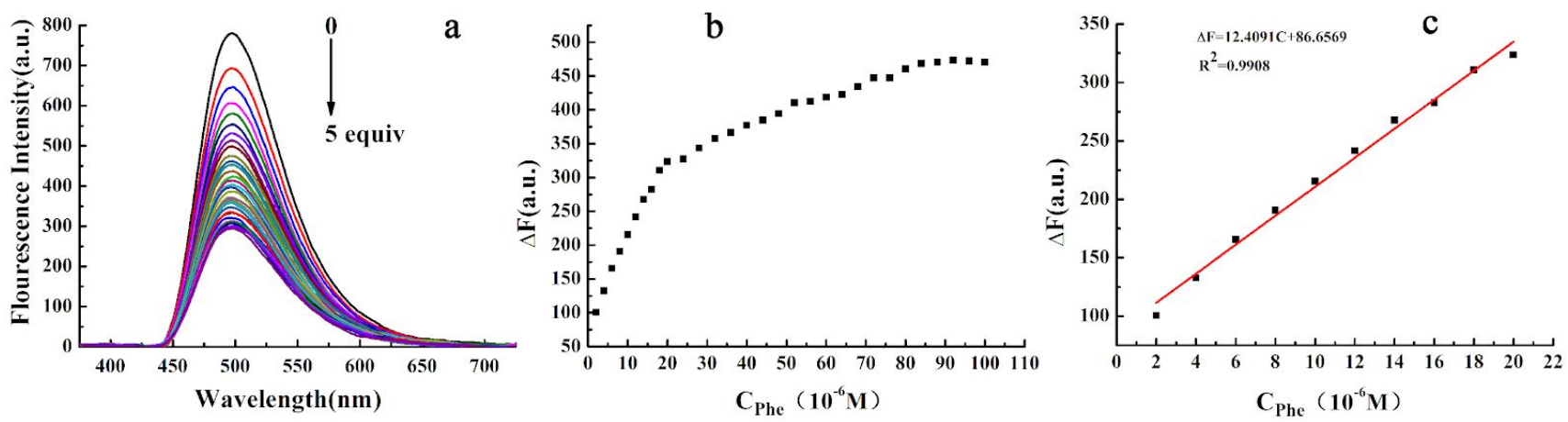
Figure 8 (a) The fluorescence spectra of Q[7]/PAL at different concentrations of Phe in aqueous solution with $\lambda=343 \mathrm{~nm}$, upon addition of increasing amounts $(0,0.10,0.20,0.30,0.40, \ldots 0.9,1.0$, 1.2, $1.4 \ldots 4.8,5.0$ equiv.) of Phe, $C_{\mathrm{Q}[7]}=2.0 \times 10^{-5} \mathrm{~mol} \mathrm{~L}^{-1}, C_{\mathrm{PAL}}=2.0 \times 10^{-5} \mathrm{~mol} \mathrm{~L}^{-1}$. (b) The corresponding plots of fluorescence intensity versus Phe concentration. (c) The plots of fluorescence intensity versus Phe concentration (from 0 to $2.0 \times 10^{-5} \mathrm{~mol} \cdot \mathrm{L}^{-1}$ )

\section{The response mechanism of the fluorescent quenching}

To understand the response mechanism of the fluorescence quenching of Q[7]/PAL on addition of Phe, we monitored the ${ }^{1} \mathrm{H}$ NMR spectra of Phe when combined with the Q[7]/PAL inclusion complex. The results revealed that all the peaks of the protons associated with the Phe were shifted to higher field relative to those of free Phe. This indicated that the Phe was located inside the Q[7] cavity (Figure. 9), whilst the movement downfield and broadening of the protons associated with PAL was consistent one included PAL molecule being replaced the Phe molecule, thereby forming a 1:1 inclusion complex.

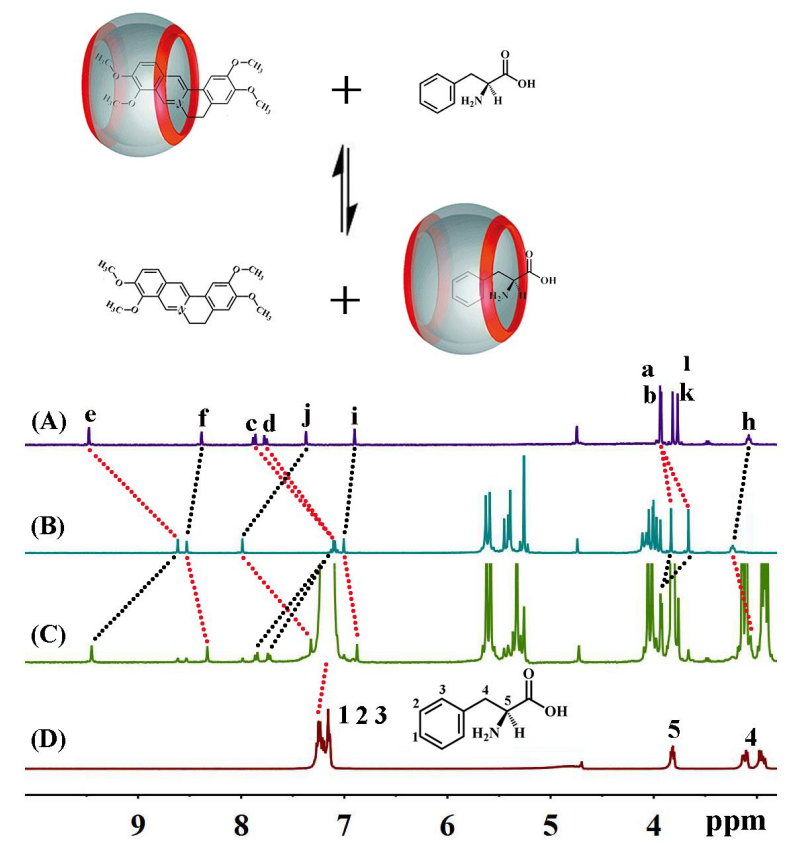

Figure 9. ${ }^{1} \mathrm{H}$ NMR spectra of Phe combined with Q[7] and PAL. ${ }^{1} \mathrm{H}$ NMR spectra of PAL (2.0 $\mathrm{mmol} / \mathrm{L})$ in the absence (A) and in the presence of 1.0 equivalents of Q[7] (B) and in the presence of 5.0 
equivalents of Phe $\left(1.0 \times 10^{-2} \mathrm{~mol} / \mathrm{L}\right)$ and in the presence 1.0 equivalents of Q[7] $(\mathrm{C})$ and neat Phe (D) in

$\mathrm{D}_{2} \mathrm{O}$ at $20^{\circ} \mathrm{C}$.

It has been documented that the fluorescence intensity associated with PAL can be greatly enhanced when it included in the hydrophobic cavity of Q[7]. ${ }^{41-43}$ A structural analysis of PAL reveals that the isoquinoline ring and the substituted benzene ring are not in a plane, and they cannot form a conjugated system, thereby resulting in the complete loss of fluorescence. When the PAL was encapsulated into the $\mathrm{Q}$ [7] cavity, the isoquinoline ring and the substituted benzene ring forms an effective conjugated system, which leads to enhancement of the fluorescence intensity. An additional factor favorable for fluorescence enhancement is that the degree of freedom of motion of the PAL molecule in the Q[7] cavity is reduced, thereby reducing the probability of radiationless transition. At the same time, the cavity can shield the excited singlet state of PAL from typical quenching processes that usually occur in an aqueous solution. Therefore, better protection was obtained leading to a greater enhancement of the fluorescence intensity of PAL. If the PAL is squeezed out by other molecules, the resulting effect will be fluorescence quenching. ${ }^{51,58,59}$

In the present study, the $\mathrm{Q}[7]$ cavity can accommodate 1.0 equiv. of PAL, forming a 1:1 host-guest inclusion complex. The protection of the Q[7] host leads to an enhancement of the fluorescence intensity of the PAL. When amino acid Phe was added to the host-guest system of Q[7]/PAL, Phe competed to occupy the Q[7] cavity. As we observed in their ${ }^{1} \mathrm{H}$ NMR spectra, the result is that the Q[7] cavity accommodated one Phe. Therefore, a stable inclusion complex was obtained leading to fluorescence quench. For the other 19 natural amino acids, they can't replace the PAL and give no fluorescence variation. This suggests there might be more stronger binding between Phe with Q[7] than the other natural amino acids, as shown in Table 1, the revealed $K_{\mathrm{a}}$ values indicated Q[7] binds with Phe with the highest binding affinity among all the natural amino acids. ${ }^{60}$

Table 1 Complex stability constant $\left(K_{\mathrm{a}}\right)$ for Q[7] with some natural amino acids
Complex
$\mathrm{K}_{\mathrm{a}}\left(\mathrm{M}^{-1}\right)$ 


\begin{tabular}{cc}
\hline Lys@Q[7] & $2.5( \pm 0.2) \times 10^{4}$ \\
Arg@Q[7] & $6.5( \pm 1.7) \times 10^{3}$ \\
His@Q[7] & $3.7( \pm 1.7) \times 10^{2}$ \\
Trp@Q[7] & $1.4( \pm 0.1) \times 10^{3}$ \\
Tyr@Q[7] & $2.2( \pm 0.7) \times 10^{4}$ \\
Phe@Q[7] & $2.3( \pm 0.8) \times 10^{5}$ \\
\hline
\end{tabular}

\section{Conclusions}

This paper has explored the binding properties of Q[7] to PAL in aqueous solution by a variety of methods. The experimental results suggest that PAL can be encapsulated into the Q[7] cavity to form a 1:1 host-guest inclusion complex. This inclusion complex PAL@Q[7] displays fluorescence of moderate intensity. Interestingly, upon the addition of Phe, a dramatic quenching of the fluorescence intensity of the inclusion complex is observed. In contrast, the addition of any other natural amino acids does not lead to any fluorescence variation. Thus, herein we have developed a fluorescence probe based on Q[7] and PAL capable of recognizing the amino acid phenylalanine.

\section{Experimental Section}

Instruments: Absorption spectra of the host-guest complexes were recorded on an Aglient 8453 spectrophotometer at room temperature. Fluorescence spectra were recorded on a Varian RF-540 fluorescence spectrophotometer. All the NMR data were recorded on a Bruker DPX 400 spectrometer in $\mathrm{D}_{2} \mathrm{O}$ at $293.15 \mathrm{~K}$.

\section{Reagents and chemicals}

$\mathrm{Q}[7]$ was prepared in our laboratory according to the literature method. ${ }^{61} \mathrm{PAL}$ and all the enantiomeric 
amino acids used in the experiment were commercially available and used as received without further purification. Stock standard solutions of PAL and all the enantiomeric amino acids $\left(100 \mathrm{mg} \cdot \mathrm{mL}^{-1}\right)$ were prepared by dissolving them in double-distilled water. Stock solution of PAL was prepared by adding double-distilled water to a final concentration of $1.0 \times 10^{-6} \mathrm{~mol} \cdot \mathrm{mL}^{-1}$. A Q $[7]$ stock solution of $1.0 \times 10^{-7}$ $\mathrm{mol} \cdot \mathrm{mL}^{-1}$ was prepared by dissolving Q[7] in double-distilled water. Stock standard solutions were

stable for several weeks at room temperature. Standard working solutions were prepared by dilution of the stock standard solutions with double-distilled water before use. All chemicals were of analytical reagent grade, and double-distilled water was used throughout the procedure.

\section{Acknowledgments}

Financial support from the National Natural Science Foundation of China (NSFC no 21861011), the Major Program for Creative Research Groups of Guizhou Provincial Education Department (2017-028), the Science and Technology Fund of Guizhou Province (No. 2018-5781) and the Innovation Program for High-level Talents of Guizhou Province (No. 2016-5657) are gratefully acknowledged. CR thanks the EPSRC for the award of a travel grant.

\section{References}

1 V. I. Chalova, I. B. Zabala-Diaz, C. L. Woodward and S. C. Ricke, World J. Microbiol. Biotechnol., 2007, 24, 353.

2 D. Kirkland and D. Gatehouse, Food and Chemical Toxicology., 2015, 84, 161-168

3 H. Förster, Aktuelle Ernährungsmedizine., 1993, 18, 331-337.

4 H. Yoshida, Y. Nakano, K. Koiso, H. Nohta, J. Ishida and M. Yamaguchi, Analytical Sciences 2001, 17, 107-112.

5 D. Wellner and A. Meister, Annual Review of Biochemistry., 1981, 50, 911-68. 
6 S. J. Barrow, S. Kasera, M. J. Rowland, Jesús del Barrio, O. A. Scherman, Chem. Rev., 2015, 115, $12320-12406$

7 K. I. Assaf, W. M. Nau, Chem. Soc. Rev.,2015, 44, 394-418.

8 C. Q. Jin, J. J. Lian, Y, Gao, K. K. Guo, K, L. Wu, L. N. Gao, X. X. Zhang, X. Zhang, Q. Y. Liu $A C S$ Sustainable Chem. Eng. 2019, 16, 13989-13998.

9 H. Liu, Y. N.Ding, B. C. Yang, Z. X. Liu, X. Zhang, Q. Y. Liu ACS Sustainable Chem. Eng. 2018, 6, 14383-14393.

10 V. Spicer, Y. W. Lao, D. Shamshurin, P. Ezzati, J. A. Wilkins and O. V. Krokhin, Analytical Chemistry., 2014, 86, 11498-11502.

11 I. Myrgorodska, C. Meinert, Z. Martins, L. le Sergeant d'Hendecourt and U. J. Meierhenrich, Journal of Chromatography A., 2016, 1433, 131-136.

12 R. Perez-Miguez, M. L. Marina and M. Journal of Chromatography A., 2016, 1428, 97-114.

13 W. Li, X. Qi, C. Y. Zhao, X. F. Xu, A. N. Tang and D. M. Kong, Mater. Interfaces., 2017, 9, 236-243.

14 Z. H. Fu, X. Han, Y. L. Shao, J. G. Fang, Z. H. Zhang, Y. W. Wang and Y. Peng, Anal. Chem., 2017, 89, 1937-1944.

$15 \quad$ K. Wang, S. Y.Zeng, H. $\quad$ L. Wang, J. $\quad$ M. Dou $\quad$ and $\quad$ J. Z. Jiang, Inorg. Chem. Front., 2014, 1, 167-171.

16 W. A. Freeman, W. L. Mock and N. Y. Shih, J. Am. Chem. Soc., 1981, 103, 7367-7368.

17 J. Kim, I. S. Jung, S. Y. Kim, E. Lee, J. K. Kang, S. Sakamoto, K. Yamaguchi and K. Kim, J. Am. Chem. Soc. 2000, 122, 540-541.

18 R. Behrend, F. Meyer and F. Rusche, Justus Liebigs Ann. Chem, 1905, 339, 1-37.

19 C. D. Gutsche, Society of Chemistry, London., 1989, 1.

20 V. Bŏhmer, Angew. Chem. Int. Ed., 1995, 34, 713-745.

21 F. A. D. de Namor, M. R. Cleverley and L. N. Z. Ormachea Chem. Rev., 1998, 98, 2495-2501. 
22 W. L. Mock and N.-Y. Shih, J. Org. Chem., 1983, 48, 3618 -3619.

23 W. L. Mock and N.-Y. Shih, J. Org. Chem., 1986, 51, 4440-4446.

24 W. L. Mock and N.-Y. Shih, J. Am. Chem. Soc., 1988, 110, 4706-4710.

25 L. Isaacs, Chem. Commun. 2009, 619-629.

26 J. Kim, I.-S. Jung, S.-Y. Kim, E. Lee, J.-K. Kang, S. Sakamoto, K. Yamaguchi, K. Kim, J. Am. Chem. Soc., 2000, 122, 540-541.

27 J. W. Lee, S. Samal, N. Selvapalam, H. Kim and K. Kim, Acc. Chem. Res., 2003, 36, 621-630.

28 L. Lagona, P. Mukhopadhyay, S. Chakrabarti and L. Isaacs, Angew. Chem., 2005, 117, 4922-4949.

29 S. Liu, C. Ruspic, P. Mukhopadhyay, S. Chakrabarti, P. Y. Zavalij, L. Isaacs, J. Am. Chem. Soc., 2005, 127, $15959-15967$.

30 M. V. Rekharsky, T. Mori, C. Yang, H. K. Young, N. Selvapalam, H. Kim, D. Sobransingh, A. E. Kaifer, S. Liu, L. Isaacs, W. Chen, S. Moghaddam, M. K. Gilson, O. Kim and Y. Inoue, Acad. Sci. USA., 2007, 104, $20737-20742$.

31 M. del Pozo, P. Hernandez and L. Hernandez. J. Mater. Chem., 2011, 21, 13657-13663.

32 S. Sonzini, S. T. J. Ryan, and O. A. Scherman, Chem. Commun., 2013, 49, 8779-8781.

33 H. Cong, L. L. Tao, Y, -H. Yu, F. Yang, Y. Du, S. F. Xue and Z. Tao, J. Am. Chem. Soc., 2009, 131, $2408-2415$.

34 J. J. Reczek, A. A.Kennedy, B. T. Halbert, and A. R.Urbach , J. Am. Chem. Soc., 2009, 131, 2408-2415.

35 J. Zhang, S. T. Coulston, R. J. Jones, J. Geng, O. A. Scherman and C. Abell., Science., 2012, 335, 690-694.

36 E. A. Appel, F. Biedermann, U. Rauwald, S. T. Jones, J. M. Zayed and O. A. Scherman, J. Am. Chem. Soc., 2010, 132, 14251-4260.

37 F. Biedermann, U. Rauwald, J. M. Zayed and O. A. Scherman, Chem. Sci. 2011, 2, 279-286.

38 R. J. Coulston, S. T. Jones, T. C. Lee , E. A. Appela and O. A. Scherman, Chem. Commun., 2011, 47, 164-166. 
39 R. Nally, O. A. Scherman, L. Isaacs, Supramol. Chem., 2010, 22, 683-690.

40 H. Yang, J. C. Hao and Y. B.Tan, Journal of Polymer Science Part A: Polymer Chemistry, 2011, 49, 2138-2146.

41 E. A. Appel, X. J. Loh, S. T. Jones, C. A. Dreiss and O. A. Scherman, Sustained release of proteins from high water content supramolecular polymer hydrogels, Biomaterials. 2012, 33, 4646-4652.

42 Y. Lan, X. J. Loh, J. Geng, Z. Walsh and O. A. Scherman, A supramolecular route towards core-shell polymeric microspheres in water via cucurbit[8]uril complexation, Chem. Commun. 2012, $48,8757-8759$.

43 E. A. Appel, X. J. Loh, S. T. Jones, F. Biedermann, C. A. Dreiss and O. A. Scherman, J. Am. Chem. Soc., 2012, 134, 11767-11773.

44 U. H.Brinker and J. L. Mieusset, John Wiley \& Sons, Ltd.: Chichester, U.K., 2010.

45 F. Hof, S. L. Craig, C. Nuckolls and J. J. Rebek, Chem., Int. Ed., 2002, 41, 1488-1508.

46 H. J. Schneider, Angew. Chem., Int. Ed., 2009, 48, 3924-3977.

47 X. Y. Huang, X. H. Zhang, T. X. Qian, J. W. Ma, L. Cui and C. J. Li, Beilstein J. Org. Chem., 2018, 14, 2236-22.

48 H. Q. Chen, J. Z. Fan, X. S. Hu, J. W. Ma, S. L.Wang, J. Li, Y. H. Yu, X. S. Jia and C. J. Li, Chem. Sci., 2015, 6, 197-202.

49 X. H. Li, X. H. Gao,W. Shi, H. M. Ma, Chem. Rev., 2014, 114, 590-659

50 M. I. Burguete, F. Galindo, S. V. Luis, L. Vigara, J. Photochem. Photobiol. A., 2010, 209, 61-67.

51 Y. X. Chang, Y. Q. Qiu, L. M. Du, C. F. Li and M. Guo, Analyst., 2011, 136, 4168-4173.

52 G. Q. Wang, Y. F. Qin, L. M. Du and Y. L. Fu, Aust. J. Chem., 2013, 66, 701.

53 Y. X. Chang, X. C. Duan, X. M. Zhang, F. Liu and L. M. Du, Aust. J. Chem., 2017, 70, 677-682.

54 C. Li, J. Li and X. Jia, Org. Biomol. Chem., 2009, 7, 2699-2703.

55 P. Giri, M. Hossain and G. S. Kumar, Int. J. Biol. Macromol., 2006, 39, 210-221.

56 C. X. Zhang, X. Jing, L. M. Du, H. L. Liu, J. Li, S. G. Zhao, Y. L. Fu, Progress in Reaction Kinetics and Mechanism.,2015, 40, 154-162. 
57 Z. Miskolczy, La'szlo' Biczo'k, Gyo"rgy Lendvay, Phys. Chem. Chem. Phys., 2018, 20, 15986-15994.

58 K. P. Wang, Y. Lei, J. P. Chen, Z. H. Ge, W.Liu, Q. Zhang, S. J. Chen and Z. Q. Hu, Dyes and Pigments., 2018, 151, 233-237.

59 K. P. Wang, S. G. Xu, Y. Lei, W. J. Zheng, Q. Zhang, S. J. Chen, H. Y. Hu and Z. Q. Hu, Talanta., 2019, 196, 243-248)

60 J. W. Lee, H. Hee, L. Lee, Y. H. Ko, K. Kim and H. I.Kim, J. Phys. Chem. B, 2015, 119, 4628-4636.

61 J. Kim, I. S. Jung, S. Y. Kim, E. Lee, J. K. Kang, S. Sakamoto, K. Yamaguchi and K.Kim, J. Am. Chem. Soc., 2000, 122, 540-541. 


\section{Synopsis}

A simple and validated fluorescence quenching method for the selective recognition and determination of the amino acid phenylalanine $(\mathrm{Phe})$ is reported.

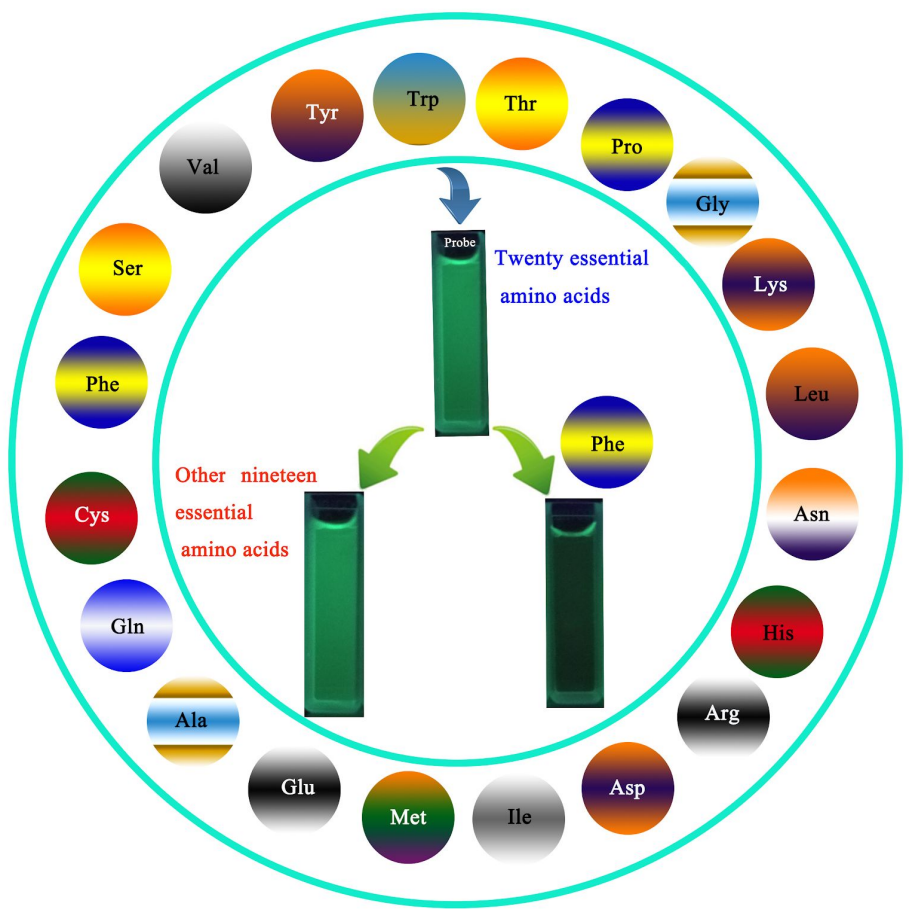

